 \\ (I..…

\section{PRODUÇÃO DO ESPAÇO EM PEQUENAS CIDADES - $O$ CASO DE CATUNDA (CE/BRASIL)}

\author{
Space production in small cities - the case of Catunda (CE/Brazil)
}

Producción de espacio en pequeñas ciudades - el caso de Catunda (CE/Brasil)

https://doi.org/10.35701/rcgs.v22n3.768

\author{
José Antônio Alves Lino 1 \\ Francisco Clébio Rodrigues Lopes²
}

Histórico do Artigo:

Recebido em 12 de Abril de 2020

Aceito em 03 de Agosto de 2020

Publicado em 30 de Dezembro de 2020

\begin{abstract}
RESUMO
A incorporação da noção de produção do espaço na Ciência Geográfica permitiu uma compreensão radical sobre a urbe, ou seja, uma análise que busca a raiz do problema mediante uma investigação de agentes, estratégias e conflitos inerentes ao processo. 0 objetivo deste artigo é estudar a expansão urbana do município de Catunda (CE), a partir do papel do Estado, e os conflitos causados pela construção da Barragem Carmina. Para tanto, contou com revisão bibliográfica, observações de campo e entrevistas com moradores. Conclui-se que é possível identificar elementos universais na urbanização da cidade pequena porque os diferentes lugares são combinações de determinações externas com elementos específicos de suas formações sociais.
\end{abstract}

Palavras-chave: urbanização; cidade local; mobilidade.

\section{ABSTRACT}

The incorporation of the notion of space production in Geographic Science allowed a radical understanding of the city, that is, an analysis that seeks the root of the problem through an investigation of agentes, strategies and conflicts inherent in the process. The objective of this article is to study the urban expansion of the municipality of Catunda (CE), based on the role of the State, and the conflicts caused by the construction of the Carmina Dam. To this end, it had a bibliographic review, field observations and interviews with residentes. It is concluded that it is possible to identify universal elements in the urbanization of the small city because the

1 Professor Mestre da Prefeitura Municipal de Catunda. Email: joseantonioalino@gmail.com,

(iD) https://orcid.org/0000-0001-5355-2616

2 Professor Doutor do curso de Geografia da Universidade Estadual Vale do Acaraú (UVA). Email: clebiolopes@yahoo.com.br, https://orcid.org/0000-0001-8173-0993 
diferente places are combinations of external determinations with specific elements of their social formations.

Keywords: urbanization; local city; mobility.

\section{RESUMEN}

La incorporación de la noción de producción espacial en la Ciencia Geográfica permitió una comprensión radical de la ciudad, es decir, un análisis que busca la raíz del problema a través de una investigación de agentes, estrategias y conflictos inherentes al proceso. El objetivo de este artículo es estudiar la expansión urbanística del municipio de Catunda (CE), a partir del papel del Estado, y los conflictos provocados por la construcción de la Represa Carmina. Para ello, se realizó una revisión bibliográfica, observaciones de campo y entrevistas con los residentes. Se concluye que es posible identificar elementos universales en la urbanización de la pequena ciudad porque los diferentes lugares son combinaciones de determinaciones externas con elementos especíicos de sus formaciones sociales.

Palabras clave: urbanización; ciudad local; movilidad.

\section{INTRODUÇÃO}

A intensificação do povoamento do território cearense ocorreu nos séculos XVIII e XIX através da doação de sesmarias pelo governo português a indivíduos que tivessem posses, com a finalidade de consolidar a ocupação da capitania do Ceará. Das 2.107 datas solicitadas, entre 1700 e 1824, 94\% tinham como justificativa a necessidade da terra para o desenvolvimento da pecuária (PINHEIRO, 2004). As fazendas de gado deram origem a muitos povoados, vilas e, depois, pequenos centros locais, que se formaram pela concentração da população em torno de uma capela, em terras doadas por um fazendeiro. A posição geográfica em relação aos eixos de comércio ou às áreas de produção regional favoreceu a projeção de algumas vilas, como a de Sobral, fundada em 1773 (SOUZA, 2005). 0 território sobralense era imenso durante o período colonial, contudo se fragmentou ao longo do século XIX, com a elevação de distritos à categoria de vilas. Esse foi o caso de Santa Quitéria, que assumiu essa condição em 1856 e aglutinava uma área correspondente à sua atual mais à de Hidrolândia, Monsenhor Tabosa e Catunda.

O município de Catunda teve sua emancipação decretada em 1990. Está localizado a 256 km da capital, Fortaleza, e é cortado pelas rodovias estaduais CE 176 (que liga o sertão de Crateús ao litoral oeste cearense) e CE 265 (que conecta o sertão central cearense à Serra da Ibiapaba). Da sua emancipação até a década de 2010, a população total cresceu 11\%, passando de 8.915 para 9.952 habitantes, enquanto a urbana variou $110 \%$, indo de 2.568 para 5.395 pessoas (IBGE, $1991,2010)$. Neste texto, trataremos da cidade, ou seja, da sede catundense, que sofreu um elevado incremento demográfico ${ }^{3} \mathrm{e}$ conta atualmente com quase 5 mil moradores.

\footnotetext{
3 Uma explicação possivel para esse fenômeno é a seletividade espacial da modernização agrícola e o desencadeamento de processos macros de expropriação e concentração fundiária, que inviabilizam a reprodução do modo de vida camponês e intensificam o êxodo rural.
} 
A urbe, em estudo, pode ser definida como uma pequena cidade, em virtude de seu contingente populacional inferior a 20 mil habitantes (SILVA, A.; GOMES; SILVA, V., 2009). Também pode ser classificada como cidade local (IBGE, 2020), pois sua influência se restringe ao seu próprio território (sede, distritos e área rural), não sendo destino principal de nenhuma outra e, geralmente, tendo outros centros de maior hierarquia como referência para atividades cotidianas de comércio e serviços da sua população.

As unidades urbanas brasileiras dessa natureza são 4.037 , cerca de $82 \%$ do total das urbes do Brasil (IBGE, 2020), e 35\% das mesmas estão no Nordeste. Elas não podem ser consideradas um conjunto homogêneo porque a reestruturação produtiva dos últimos anos permitiu 0 estabelecimento de filiais de indústrias, o desenvolvimento da agricultura e a extração de minerais, o que Ihes conferiu novos papéis na divisão territorial do trabalho. Contudo, uma parcela significativa continua apresentando características semelhantes, por exemplo, a falta de emprego para sua população ativa e a dependência dos empregos públicos, aposentadorias e políticas sociais, como o Programa Bolsa Família (PBF) e o Benefício de Prestação Continuada da Assistência Social (BPC).

O cotidiano nessas localidades apresenta singularidades, como o fechamento dos estabelecimentos comerciais e de serviços para realização da sesta; o encerramento das atividades cotidianas a partir das dez da noite, com exceção dos dias festivos; o reconhecimento das diferentes badaladas do sino da igreja, diferenciando as missas dos enterros; a tênue fronteira entre o espaço público e o privado, porque a calçada é usada para conversar, fazer artesanato, secar roupa, comer e armar rede nas sombras das árvores; a relevância do dia da feira, marco na semana, tanto para os habitantes da sede quanto das áreas rurais; e, por fim, a ruptura com a rotina provocada pelas festas, visto que a população recebe parentes e amigos de outros lugares e 0 Centro é ornamentado para as festividades (SANTANA, 2011). No entanto, já é possível perceber elementos de uma sociedade urbana ${ }^{4}$, como 0 consumo de produtos industrializados e o excesso de resíduos sólidos não orgânicos; a presença de células de facções criminosas, com venda de drogas ilícitas, assassinatos e assaltos; o uso das redes sociais, ainda que por meio de uma conexão de baixa qualidade; a preocupação com a estética corporal e a instalação de academias de ginástica; e, ainda, a oferta de cursos de graduação e pós-graduação na modalidade de ensino à distância.

\footnotetext{
${ }^{4}$ Sociedade urbana é a que nasce da industrialização, marcada pela homogeneidade e complexificação múltipla que atinge 0 espaço e o tempo simultaneamente. 0 homogêneo corresponde a alguma coisa: por um lado, vontades, estratégias unitárias, lógicas sistematizadas; por outro, representações redutoras e, consequentemente, simplificadoras (LEFEBVRE, 2004).
} 
Tratar da produção do espaço significa refletir sobre a ação de agentes que individualmente ou coletivamente contribuem para que o decurso ocorra, portanto requer uma análise das práticas que levam a um processo contínuo de incorporação de terras, deterioração de certas áreas, renovação urbana, relocação desigual de infraestrutura e mudança do conteúdo social e econômico de porções da cidade. Numa sociedade burguesa, o espaço "[...] tende para um código único, para um sistema absoluto, o da troca e do valor de troca, da coisa lógica e da lógica coisa" (LEFEBVRE, 2004, p. 153).

Corrêa (1989) estabeleceu os proprietários dos meios de produção, os proprietários fundiários, os promotores imobiliários, o Estado e os grupos excluídos como os agentes que fazem e refazem a cidade. A sua formulação teórica tem a metrópole carioca como observação empírica, portanto a transposição dessa grade conceitual a outras realidades exige uma adaptação.

Nas pequenas cidades do sertão cearense, a dinâmica urbana depende muito das obras estatais ${ }^{5}$ porque elas mobilizam reservas fundiárias públicas, afetando o preço da terra, deslocando pessoas e abrindo áreas de expansão. Catunda, por exemplo, foi impactada pela construção da Barragem Carmina e, consequentemente, a desapropriação de várias famílias, que ocupavam localidades rurais alagadas pelo espelho d'água, e o reassentamento delas nos bairros Bela Vista e Passagem.

Este artigo $^{6}$ tem como objetivo analisar o papel do Estado na expansão urbana de Catunda e as contradições inerentes, por isso contou com pesquisa bibliográfica, trabalho de campo e realização de entrevistas com moradores. Ele está organizado em quatro seções: a primeira, que é esta introdução, apresenta informações preliminares; a segunda descreve o espaço urbano catundense, isto é, o conjunto dos bairros que compõem a urbe; a terceira aborda a expansão urbana e os conflitos, a partir da construção da Barragem Carmina; por fim, seguem as considerações finais.

\section{Discussões introdutórias sobre o espaço urbano de Catunda}

A Geografia tem a dimensão espacial da objetivação humana como foco de suas análises, pois o espaço geográfico é produto do trabalho que se fixou na natureza. Ele também é o meio onde a espécie humana se transforma e modifica o ambiente, na sua luta pela subsistência e pela

\footnotetext{
${ }^{5}$ Buscamos superar uma noção abstrata de Estado ao longo da exposição, pois temos consciência que suas ações são impulsionadas por sujeitos reais que travam embates para defender os seus interesses de classe.

${ }^{6}$ Os dados tratados neste texto são provenientes de uma dissertação de mestrado intitulada Ocupação e expansão urbana em Catunda/CE: uma análise do crescimento dos bairros Bela Vista e Passagem, defendida por Lino (2020), no Mestrado Acadêmico em Geografia da Universidade Estadual Vale do Acaraú.
} 
apropriação desigual dos frutos da atividade laboral. Por último, é condição para desenvolvimento da economia, visto que facilita a circulação mercantil ao aproximar a produção do consumo. $\mathrm{Na}$ cidade, ele tem uma estrutura, ou seja, não está organizado ao acaso, porque sujeitos, estratégias e determinações de cada período da organização social se ligam a ele.

O espaço urbano aparece como um conjunto de fragmentos justapostos entre si. Tal fragmentação responde ao imperativo da propriedade privada, que define os usos de cada porção da cidade conforme o preço mais alto que se está disposto a pagar pela terra, nas atuais circunstâncias do terreno e do solo. Assim, as áreas são organizadas hierarquicamente como terciárias, residenciais, industriais e de reserva para futura expansão. 0 estudo dessa organização envolve a relação entre o centro, os bairros e a periferia, bem como os papéis que desempenham. Por isso, faremos uma descrição dessas formas espaciais e de suas funções, com o objetivo de apreender o conjunto urbano.

A ocupação da sede teve início nos primeiros anos do século XX, com a chegada de famílias do município cearense de Santa Quitéria e a implantação da fazenda Santa Madalena, embrião do atual núcleo urbano. Aos poucos, os herdeiros desse latifúndio foram vendendo partes dessa gleba para outras famílias, contudo a propriedade permaneceu concentrada nas mãos de poucos grupos familiares, que controlam o ritmo de expansão da mancha urbana.

A formação dos bairros ocorreu sem um planejamento que estruturasse os limites, 0 arruamento e o acesso dos lotes às principais vias municipais. No entanto, "[...] esses pedaços da realidade social" (SOUZA, 1989, p. 149) não apresentam somente uma dimensão objetiva, mas também uma subjetiva, logo são importantes nos estudos urbanos, já que carregam uma dinâmica própria, onde o cotidiano se torna mais perceptível (LOPES, 2014). Em Catunda, eles são: Centro, Beira Rio, Caixa D'Água, Açude, Passagem e Bela Vista (ver figura 1) e possuem uma identidade que se confunde com vínculos familiares e tradições religiosas.

Cada bairro é personificado pelas famílias mais antigas, assim o Bela Vista é o local dos Matias, Caetanos e Abreus; o Beira Rio é o dos Calistos, Ferreiras e Medeiros; o Caixa D’Água é o dos Naus e Liras; e o Açude é o dos Alves. A única exceção é o Centro, que se apresenta como 0 integrador de toda a comunidade urbana. Algo também interessante é a toponímia dos lugares, porque remete a aspectos naturais (rio, passagem, vista e açude), o que evidencia a forte presença da natureza na cidade. Passaremos a um relato dos elementos objetivos. 
Figura 1: Bairros de Catunda - CE.

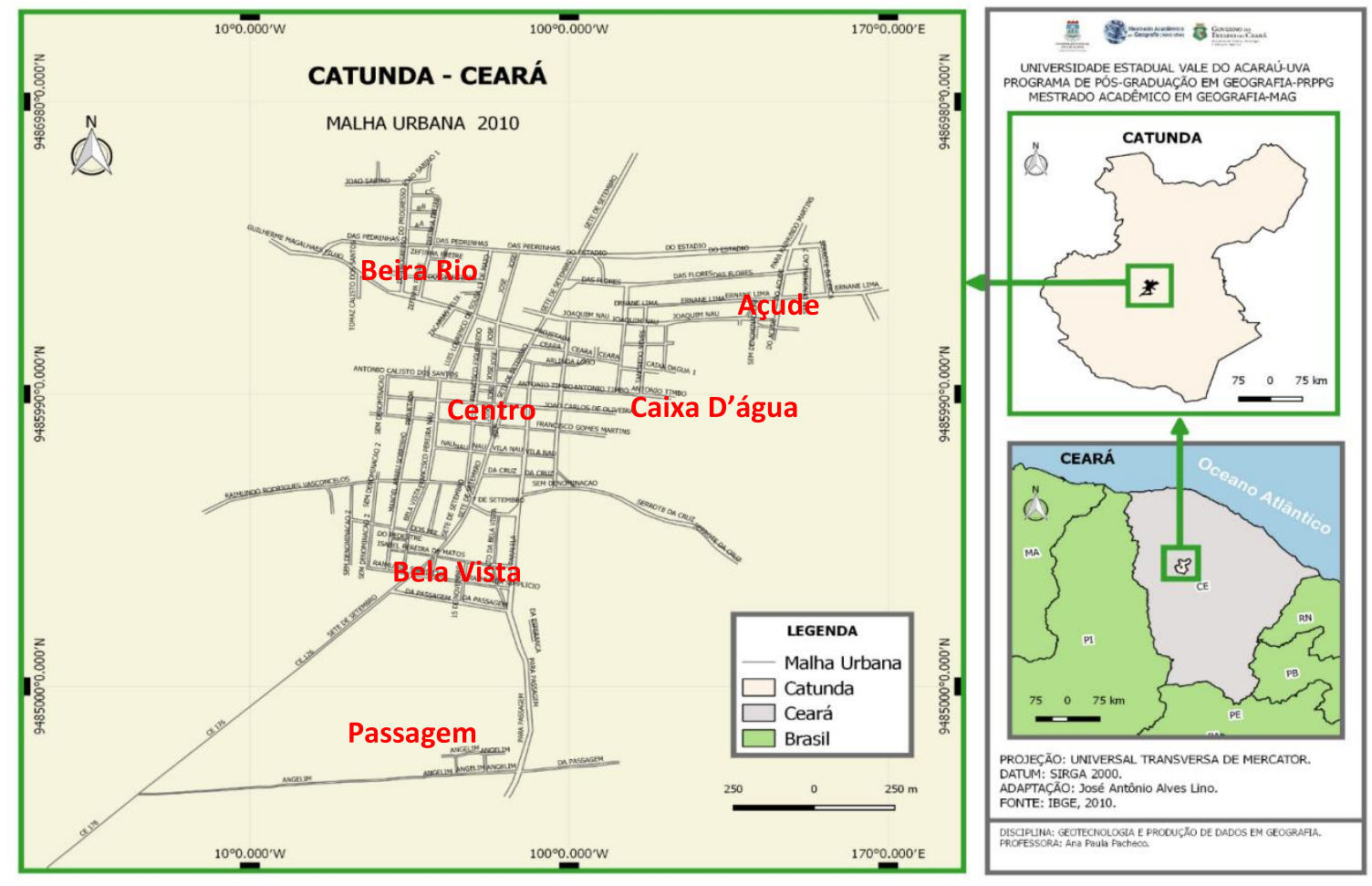

Fonte: Lino (2020).

O Centro "[...] designa ao mesmo tempo um local geográfico e um conteúdo social" (CAS-

TELLS, 1983, p. 311) porque os sentidos da centralidade urbana se fixam num certo ponto do espaço. Dessa forma, ele é caracterizado pela concentração das atividades comerciais, de serviço, da gestão pública, culturais e de transportes. Guarda uma parte considerável das residências, já que possui 983 habitantes, distribuídos em 355 residências, com média de 3,2 moradores por domicílio (IBGE, 2010). Ele tem fraca centralidade, pois é referência apenas para os moradores do próprio município, contudo é a porção mais bem dotada de infraestrutura urbana (iluminação pública, pavimentação e saneamento básico), logradouros públicos e imóveis de aluguéis (ultimamente, quitinetes são construídas sobre os prédios comerciais).

O Beira Rio foi impactado pela construção do Conjunto Habitacional Francisco Antônio Lima, em 2002, e a chegada de 54 famílias, oriundas de diferentes localidades de Catunda. Apesar da tentativa de oferecer o "bem-estar social" a essas famílias, que viviam em condição de moradia de aluguel, em residências precárias, o conjunto acabou levando-as a uma condição de segregados. $O$ projeto habitacional tem casas de cinco cômodos (sala, cozinha, dois quartos e banheiro) e não possui rede de esgoto, acesso pavimentado, coleta seletiva de lixo, escola, creche e posto de saúde, o que ratifica o caráter monofuncional do urbano. Em 2013, a segunda etapa foi entregue e totalizou uma expansão de $20.000 \mathrm{~m}^{2}$ na área territorial do bairro. 0 desnivelamento do 
terreno, a proximidade com o cemitério e a presença de olarias são fatores que conferem um valor venal menor da terra na área, por isso foi ocupado por uma população mais proletarizada, que totaliza 1.034 habitantes, distribuídos em 343 domicílios, com uma média de 3,5 moradores por domicílio (IBGE, 2010).

O Caixa D'água foi formado por famílias que procuravam morar próximo ao Centro, pois o bairro se localiza em sua periferia imediata. A sua população é de 785 habitantes, distribuída em 251 habitações, com média de 3,6 moradores por residência (IBGE, 2010). O seu crescimento demográfico está atrelado à presença da Escola de Ensino Fundamental I Berlamina Nau e a necessidade de habitar nas proximidades do equipamento, em virtude da dificuldade com os deslocamentos. Tal fato aparece num percentual maior de jovens, pois $28,9 \%$ da população é formada de pessoas que possuem de 0 a 14 anos, enquanto os idosos (acima de 65 anos) representam $10,8 \%$ do total (IBGE, 2010). Além da caixa d'água, que dá nome ao bairro, e da escola, o local conta com um ginásio poliesportivo, um posto de saúde e pequenos comércios que abastecem a sua população.

O Açude foi um dos primeiros a se formar, depois do Centro, contudo possui a menor população, com 452 habitantes, distribuída em 136 casas, com média de 3,8 moradores por domicílio (IBGE, 2010). A construção de um pequeno açude serviu como atrativo porque as famílias usavam o recurso para dessedentação de animais, atividades agrícolas, lavagem de roupa e lazer, por isso a ocupação se iniciou nas proximidades do recurso hídrico e se estendeu em direção à área central da cidade. Muitos servidores públicos, dentre eles o atual prefeito, se mudaram para o bairro no final da década de 1990, o que causou um aumento da abertura de lotes e a realização de algumas obras públicas (pavimentação, canalização de água e esgoto nas principais vias, construção de um ginásio poliesportivo e de uma areninha ${ }^{7}$ e implantação da Câmara dos Vereadores).

Passagem possui uma população de 631 habitantes, 186 domicílios e uma média de 4 habitantes por domicílio (IBGE, 2010), portanto é o que possui a maior densidade habitacional dentre os bairros. Ele passou por transformações significativas após a construção da Barragem Carmina e o reassentamento de moradores que habitavam as comunidades de Jardim, Rodilho, Pé da Serra e Trapiá, atingidas pelas águas do represamento. Apesar da instalação da infraestrutura básica de água e energia, a área é carente de posto de saúde, pavimentação das ruas e espaços de lazer. As famílias vivem de aposentadorias do Instituto Nacional do Seguro Social (INSS), programas sociais como o PBF, venda de pescado e pequenos comércios.

\footnotetext{
${ }^{7}$ Areninha é um equipamento público de lazer construído pelo governo estadual em parcerias com as prefeituras e conta com campo de grama sintética, calçadão, parque infantil, academia ao ar livre e bancos.
} 
Bela Vista possui 1.028 habitantes, 352 domicílios e média de 3,3 moradores por habitação, logo é o segundo mais populoso da cidade. É visível o volume de construções, por isso ele abriga 3 das 11 lojas de materiais de construção da cidade - Depósito Bela Vista, Bazar da Construção e Oliveira Material de Construção. Um equipamento público de referência é o Hospital Geral de Catunda, inaugurado em 1988 e gerador de uma centralidade, pois bares, pizzarias, padaria, supermercados e a Rádio Comunitária Planalto FM se instalaram na área, além da Praça da Saúde, considerada um cartão postal, que foi construída. Assim como Passagem, o bairro teve a sua expansão afetada pela chegada das famílias desapropriadas pela Barragem Carmina que não aceitaram morar no reassentamento e, com a indenização de $R \$ 5.000,00$, compraram um lote na periferia e construíram suas moradias.

Os bairros possuem uma importância na estruturação das cidades, pois, enquanto locais de moradias atrelados a um conteúdo social, guardam traços fundamentais das classes a eles circunscritos, ajustando os indivíduos ao comportamento coletivo do grupo ao qual fazem parte e, simultaneamente, reproduzindo-os (O'NEILL; NATAL, 1988). Passaremos a uma análise das contradições da produção do espaço a partir da construção de uma represa nas proximidades da sede urbana.

\section{Barragem Carmina - expansão urbana e conflitos sociais}

O Açude Carmina foi construído entre 2001 e 2002 pelo governo estadual ${ }^{8}$, tem capacidade de armazenamento de 13 milhões de $\mathrm{m}^{3}$ de água e é gerenciado pela Companhia de Gestão dos Recursos Hídricos (COGERH) e pela Superintendência de Obras Hidráulicas (SOHIDRA). A barragem impactou na extensão do tecido urbano do município (ver figura 2) porque a construção desse equipamento obrigou a transferência de famílias de áreas rurais alagadas para reassentamentos urbanos.

\footnotetext{
${ }^{8} \mathrm{~A}$ barragem se insere num conjunto de respostas estatais desenvolvidas ao longo de todo o século XX, no Nordeste, com o objetivo de criar um paliativo aos efeitos da perda de lavouras e desempregos ocasionados pelas estiagens. A construção de açudes e estradas serve como política de emprego de curto prazo, que assegura a reprodução da força laboral, desempregada pelas secas e, dessa forma, reduz os custos dos latifundiários. A mão de obra retida na região pode retornar aos seus antigos locais de trabalho após a seca (MARTINS, 2004).
} 
Figura 2: Proximidade entre a Barragem Carmina e a mancha urbana de Catunda - CE, 2019.

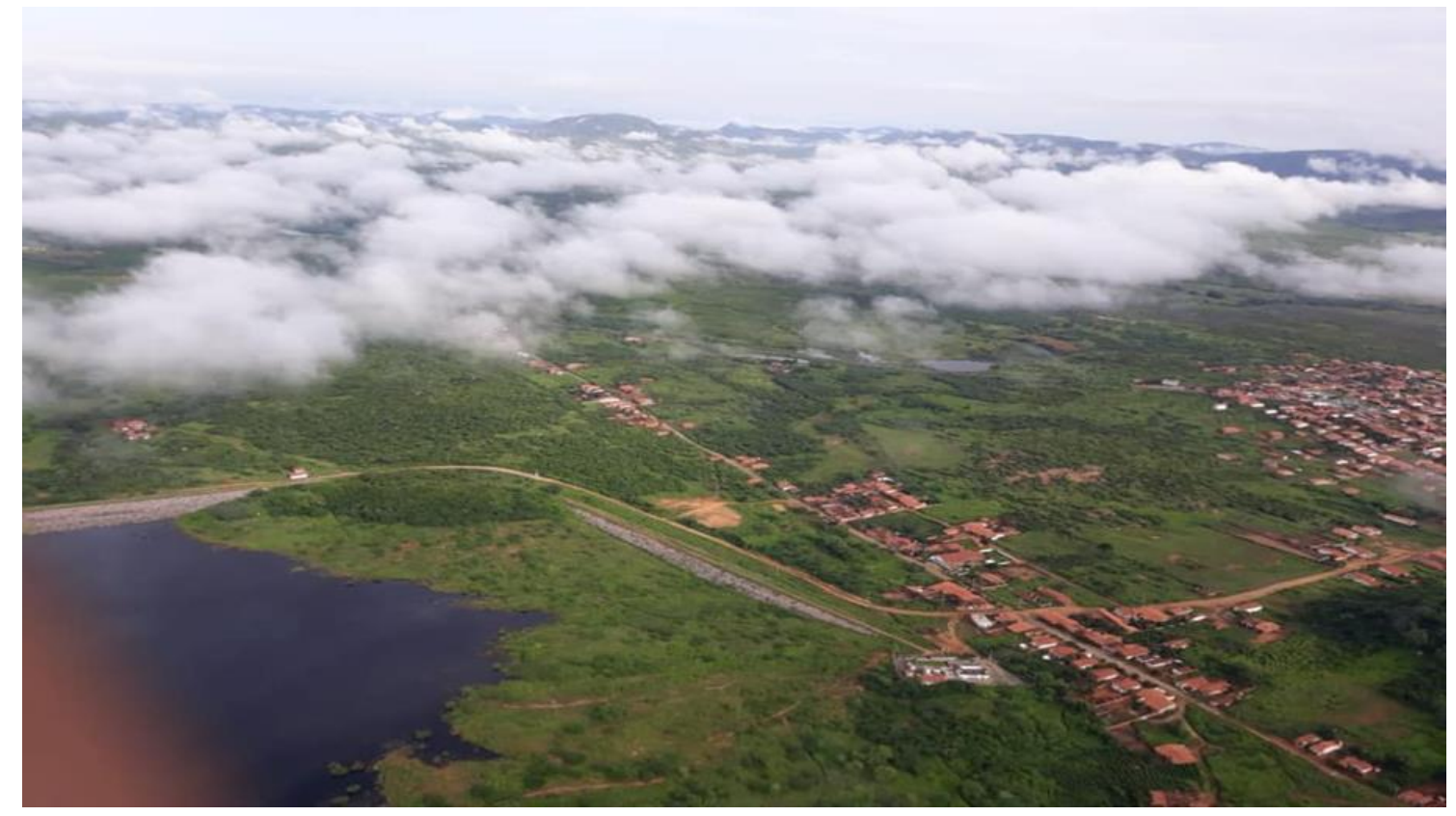

Fonte: Lino (2020).

A construção da barragem foi marcada pela desinformação dos principais afetados, como nos revelou um entrevistado:

[...] a gente achava que era só conversa de novo, mas quando começaram a aparecer uns homens do governo por lá, pelo Jardim, subiram para os Rodilhos, eles andavam tudo ali, aí a gente começou a desconfiar que a coisa ia ser de vera. Quando, no finalzinho do ano de 2000, começaram a chegar máquinas. Primeiro, chegou só um trator de esteira e uma caçamba, vieram fazer um acampamento, que era onde os homens iam ficar, mas quando foi no mês de maio, aí danou-se a chegar maquinário de todo jeito e está aí: 0 açude feito e nós aqui morando nesses casebres, só com saudade do nosso lugar (J. de S. O.; entrevista realizada em 23/11/2019).

Em virtude da falta de informações, as obras pareciam surgir do nada e o deslocamento se tornou a única saída, porque o sentimento de insegurança se instaurou na população a ser removida. Assim, as comunidades de Jardim, Rodilho, Pé da Serra e Trapiá tiveram seus costumes, identidades e modos de vida levados pelas águas do represamento do rio dos Macacos. Os pequenos proprietários de terras e os camponeses não proprietários foram os mais atingidos porque tiveram que escolher entre a indenização em dinheiro ou uma casa, num conjunto habitacional denominado Agrovila (ver figura 3), localizado no bairro Passagem. 
Figura 3: Agrovila em Catunda - CE, 2019.

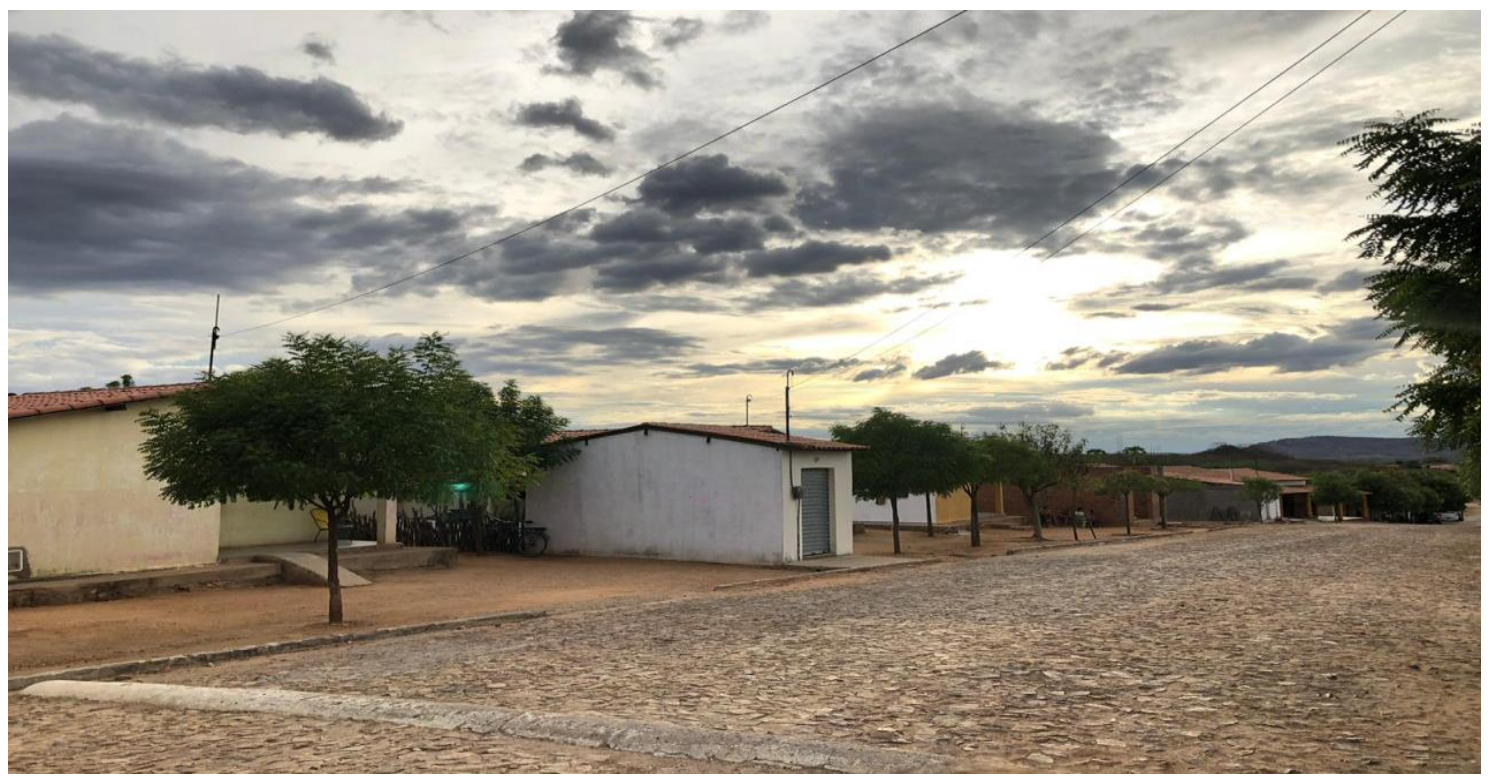

Fonte: Lino (2020).

A migração se apresentou como única alternativa às famílias porque a indenização, no valor médio de $\mathrm{R} \$ 5.000,00$, impossibilitou a aquisição de uma propriedade rural, logo elas foram obrigadas a sair de suas terras para dar espaço ao lago da barragem. Tal fato apareceu no depoimento de um dos moradores da Agrovila:

A gente, que recebeu a casa ao invés de pegar os $R \$ 5.000,00$, não tinha outra opção. Se nós pegássemos os 5.000 , nós não conseguíamos fazer a casa e ia ficar morando de favor novamente, ou então tinha que ir embora daqui para outro lugar, procurar outra fazenda para gente trabalhar e morar. Então, a maioria não quis o dinheiro por isso mesmo (R. C. S.; entrevista realizada em 24/09/2019).

A moradia na cidade inviabilizou os meios de subsistência das famílias porque a reprodução econômico-social se fazia por meio do trabalho na terra, da criação de animais e da vida no campo. 0 estilo de viver simples representava uma menor dependência externa, já que a subsistência era garantida por aquilo que era plantado e colhido, embora os períodos de estiagem pudessem alterar esse microcosmo. Dessa forma, o deslocamento apareceu como uma possibilidade de novas oportunidades, contudo a insatisfação veio com a entrega da nova moradia, como nos relatou um morador da Agrovila:

Olha seu José, quase ninguém ficou satisfeito, a não ser os donos das terras. Quem tinha muita terra ganhou muito dinheiro, mas nós, que éramos só moradores, nós só ganhamos essa casinha aqui na vila e foi para viver nesse estado que você vê aqui. No começo, todo mundo pensava que eles iam dar um terreno, a gente lá noutro lugar no mato, onde a gente pudesse criar animais, produzir nosso alimento, mas não, colocaram a gente foi aqui nesse lugar, na beira da rua [...] (J. F. J. S.; entrevista realizada em 27/09/2019). 
Estar na beira da rua, como apareceu no relato, significa uma moradia desprotegida de todos os elementos que marcavam o local anterior. A moradia, reduzida a casa, não dava conta das necessidades das famílias porque se tratava de uma forma artificialmente planejada, que impõe a todos uma única maneira de viver. O novo lugar não contava com elementos urbanos básicos, como rede de esgoto e pavimentação das ruas.

Aos poucos, alguns equipamentos foram sendo instalados, como a Escola de Ensino Fundamental Camelo Gomes e pequenos comércios, que contribuíram com a mobilização de terrenos próximos e a construção de casas fora da Agrovila. $\mathrm{O}$ açude representou a possibilidade de novos negócios urbanos aos proprietários fundiários, mas colocou as pessoas atingidas ${ }^{9} \mathrm{em}$ situação de risco, insegurança e gerou conflitos vinculados às indenizações irrisórias e à carência dos assentamentos que dificultavam a adaptação. Dessa forma, a reflexão sobre a produção do espaço não se encerra em seus aspectos formais, como as modificações no tecido da cidade, e sim nos seus elementos profundos e contraditórios.

\section{CONSIDERAÇÕES FINAIS}

A produção do espaço nas pequenas cidades parece ocorrer num ritmo mais lento do que nos grandes centros, por isso as reestruturações se dão com pouca frequência e a possibilidade de converter terra rural em urbana explica a verticalização incipiente. Apesar da fraca centralidade desses lugares, a implantação de obras públicas, como a construção de um conjunto habitacional, um equipamento de saúde ou uma barragem, é capaz de abrir novas fronteiras de capitalização fundiária.

Do ponto de vista das relações de sociabilidade, o entrelaçamento entre vínculos familiares e a constituição dos bairros propicia uma maior proximidade entre os moradores e laços de solidariedade mais intensos. Contudo, a lógica sistematizada da abstração mercantil que impera na sociedade urbana começa a corroer esses liames. A urbanização de Catunda deve ser compreendida na sua singularidade, visto que representa o encontro das determinações homogêneas do modo de produção com elementos específicos das sociedades constituídas no sertão cearense.

A área urbana catundense é marcada pela estrutura centro-periferia, com a área central mais bem equipada e os bairros Beira Rio, Caixa D'Água, Açude, Passagem e Bela Vista

\footnotetext{
9 Dependendo do observador, os atingidos são considerados como beneficiários porque a nova vida se apresenta como um mérito concedido às famílias pelo Estado, que viviam anteriormente em condições consideradas inferiores (BORTONE; LUDWIG; XAVIER, 2016).
} 
desigualmente assistidos por elementos de urbanidade. Dessa forma, a implantação de uma grande obra, como a Barragem Carmina, é capaz de alterar o tecido urbano, em virtude das infraestruturas necessárias para viabilizá-la economicamente. Além disso, a represa alterou modos de vida, com a mobilidade forçada de comunidades do campo para cidade. A (des)integração desses sujeitos ao urbano gerou conflitos sociais porque eles foram colocados "na beira da rua", isto é, desprovidos simultaneamente dos elementos que constituíam a vida camponesa anterior e dos necessários à nova na urbe.

A finalidade deste texto foi refletir sobre o papel contraditório do Estado na expansão urbana e podemos concluir que características da urbanização capitalista se reproduzem em diferentes localidades, independente do tamanho demográfico desses locais.

\section{REFERÊNCIAS}

BORTONE, F. A. S; LUDWIG, M. P; XAVIER, K. D. Contradições da modernização no processo de des/re/territorialização do lugar: o caso dos atingidos pela construção da Hidrelétrica Cadonga. Revista ELO Diálogo em Extensão, Viçosa-MG, v. 5, n. 2, p. 1-12, 2016.

CASTELLS, M. A Questão Urbana. Rio de Janeiro: Paz e Terra, 1983.

CORRÊA, R. L. O Espaço Urbano. São Paulo: Ática, 1989.

IBGE - Instituto Brasileiro de Geografia e Estatística. Censo Demográfico 1991: resultados da amostra, Ceará, Municípios. Rio de Janeiro: IBGE, 1991.

Censo Demográfico 2010: resultados da amostra, Ceará, Municípios. Rio de Janeiro: IBGE, 2010.

Regiões de influência das cidades: 2018. Rio de Janeiro: IBGE, 2020.

LEFEBVRE, H. A Revolução Urbana. 2a . Reimpressão. Belo Horizonte: UFMG, 2004.

LINO, J. A. A. Ocupação urbana em Catunda/CE: uma análise do crescimento dos bairros Bela Vista e Passagem. 2020. 146 f. Dissertação (Mestrado Acadêmico em Geografia), Universidade Estadual Vale do Acaraú, Sobral-CE, 2020.

LOPES, F. C. R. O bairro como escala. GEOUSP, São Paulo, v. 18, n. 2, p. 288-297, 2014.

MARTINS, A. L. M. Estado e força de trabalho no Nordeste: ocupação no setor público e aposentadorias rurais na década de 1990. 2004. 150 f. Tese (Doutorado em Economia Aplicada) - Instituto de Economia, Universidade Estadual de Campinas, Campinas-SP, 2004.

O'NEIL, M. M; NATAL, M. C. Mobilidade Residencial: alguns comentários. Revista Brasileira de Geografia, Rio de Janeiro, v. 50, n. 2, p. 125-132, 1988.

PINHEIRO, F. J. Mundos em confrontos: povos nativos e europeus na disputa pelo território. In: SOUSA, S. de (Org.). Uma Nova História do Ceará. 3. ed. Fortaleza: Edições Demócrito Rocha, 2004. p. 17-56.

SANTANA, A. N. C. Pequenas cidades do Ceará no (des)encontro do urbano e do rural: Groaíras e Meruoca em discussão. 2011. 235 f. Tese (Doutorado em Geografia), Universidade Federal Fluminense, Niterói-RJ, 2011. 
SILVA, A. B. da; GOMES, R. de. C. da. C; SILVA, V. P. da. Por uma concepção conceptual: as pequenas cidades em tela. In: (Org.). Pequenas cidades: uma abordagem geográfica. Natal: EDUFRN, 2009. p. 43-58.

SOUZA, M. L. de. O bairro contemporâneo: ensaio de abordagem política. Revista Brasileira de Geografia, Rio de Janeiro, v. 2, n. 51, p. 139-172, 1989.

SOUZA, M. S. de. Ceará: bases de fixação do povoamento e o crescimento das cidades. In: SILVA, J. B. da. et al. (Org.). Ceará: um novo olhar geográfico. Fortaleza: Edições Demócrito Rocha, 2005. p. 13-31. 